\title{
Homofilia e homossexualidades: recepções culturais e permanências
}

\section{Homophily and homosexualities: cultural receptions and continuities}

Resumo: Fogem ao objetivo deste trabalho a completa historicização das homossexualidades (gays, lésbicas, travestis, transexuais, intersexuais, HSH, etc.), tomadas enquanto categorias identitárias, e suas distintas representações ao longo do tempo. O propósito é demonstrar que essa conotação identitária, sobretudo de identidade desqualificada, é algo contingencial e histórico, moldado sobre as dificuldades de cada grupo social em lidar com a diferença. Intrinsecamente ligadas à estruturação social global, tanto suas formas de representação, as sanções que lhes foram atribuídas, assim como os modos de suas assimilações são culturalmente variáveis.

Palavras-chave: História da homossexualidade; Orientação sexual; Estigmatização.

Abstract: The complete historicizatization of homosexualities (gays, lesbians, travesties, transsexuals, intersex, MSM etc.) as identity categories and its different representations over time is not the objective of this work. My objective is to demonstrate that these connotations of identity, in special the disqualified identity, are something contingent and historical, forged under the difficulties of each social group to deal with the difference. Intrinsically linked to the global social organization, both their forms of representation, the sanctions that have been assigned to them, as well as their modes of assimilation can vary culturally.

Keywords: history of homosexuality; sexual orientation; stigmatization.

O dever do historiador é dar à sociedade que é sua o sentimento da relatividade de seus valores.

(VEYNE, 1987, p. 44)

\section{Introdução}

Como todas as práticas desviantes, aquilo que, por mera facilidade linguística, nomeio homossexualidades ${ }^{1}$ somente o é na exata medida do modo de fixação da norma hegemônica. Nessa qualidade, já foram elas representadas pelas culturas de matriz judaico-cristã como imoralidade,

\footnotetext{
* Mestre em Política Social pela Universidade Federal Fluminense (UFF). Doutoranda - Programa de Pós-graduação em História Social - da UFF, Campus do Gragoatá. Rua Prof. Marcos Waldemar de Freitas Reis, Bloco O, sala 501, CEP 24210-380 - Niterói - RJ. Bacharel em Ciências Sociais e Jurídicas pela Universidade Federal do Rio de Janeiro (UFRJ). E-mail: ritacolacobr@yahoo.com.br.
} 
pecado, vício, exacerbação dos desejos da carne e crime. Em outras culturas e tempos históricos, entretanto, encontravam-se completamente integradas à estrutura social (CARDÍN, 1984; RICHARDS, 1993; MOTT, 1994, p. 2-6). Na região da América Latina, por exemplo, o antropólogo Luiz Mott empreendeu ampla revisão bibliográfica das pesquisas que documentam a notoriedade das práticas homófilas e sua assimilação cultural entre os povos originários da região conquistada (MOTT, 1994, p. 1-15).

No que concerne às sanções e ao modo de sua aplicação, elas igualmente sofrem alterações, de acordo com o período histórico, a região e, sobretudo, o status social dos envolvidos. Entre o século IV até o fim da vigência do Tribunal do Santo Ofício, em 1821, por exemplo, têm-se morte na fogueira, decapitação, expropriação de bens, flagelações públicas, desterro, penitência, reclusão e castração (FOUCAULT, 2005; MOTT, 1994; VAINFAS, 2004; 1992; BELLINI, 1987; BROWN, 1987; RICHARDS, 1993; LAQUEUR, 2001; LOPES, 2012).

Com o crescimento do conhecimento científico no século XIX, verifica-se uma notável intervenção transdisciplinar: médicos, juristas, psiquiatras e peritos criminais (médicos e antropólogos) compuseram um vasto discurso sobre diagnóstico, etiologia e capacitação para a "cura" desta condição. O objetivo era readequar ao padrão hegemônico o que era nomeado como desvio, inversão, vício, degeneração, desequilíbrio endócrino, psicopatia, depravação, corrupção psicológica e perversidade de ordem sexual (LAQUEUR, 2001). Os métodos empregados se sofisticam: "sucos de vários órgãos de animais" para combater uma presumida disfunção hormonal; choques elétricos; confinamento psiquiátrico; choques hipoglicêmicos mediante ingestão de insulina; indicações de transplantes de testículos e de ovários; propostas de criação de manicômios exclusivos para ambos os sexos; proposta de lei tipificando as práticas masculinas que provocassem escândalo público como delitos; "camisas-de-força química"; prisão e trabalhos forçados por atos sexuais entre homens, ainda que praticados por agentes maiores e de comum acordo, no âmbito de suas privacidades; prisão por imputações "úteis", ainda que não provada a materialidade (abuso sexual de crianças, assassinatos, etc.); expropriação de bens; destituição da capacidade civil, possibilitando que familias mantivessem seus membros indesejáveis confinados, passando a gerir e fruir seus patrimônios. Somente no período compreendido entre os anos 1960/70 há: dessensibilização sistemática, calcada em técnicas de recondicionamento (via eletrochoques, associação de imagens; terapia de aversão por ingestão de substâncias químicas); seccionamento do hipotálamo, praticada pelo Dr. Fritz Roeder e noticiada em publicação médica oficial estadunidense de 25/09/1970, em tudo semelhante à lobotomia pré-frontal (WIENBERG, 1977, p. 53-68). 
Internamentos em instituições psiquiátricas, com as consequentes interdições de direitos civis, são relatados no Brasil desde os anos de 1935 (GREEN, 2000, p. 187-190; jornal Lampião da Esquina, n. ${ }^{\circ}$ 32). Esse leque de ações visando ao reenquadramento às normas hegemônicas de orientação sexual e gênero contribuiu para aprofundar e consolidar o estigma, a segregação e, consequentemente, a vulnerabilização às múltiplas formas de violência, que ainda hoje vemos ser intensivamente praticadas (TREVISAN, 2000, p. 186-2133; GREEN, 2000, p. 191-249).

\section{Dificuldades com a diferença}

O conflito diante da sexualidade e do corpo remonta à cultura hebraica, forjada pela religião judaica. Sistematizada no Velho Testamento bíblico, sua estruturação se organiza em torno das noções de pureza e impureza; a prática do impuro implica abominação. É impureza, por exemplo, comer sangue; tocar ou copular com a mulher quando menstruada; copular com a mulher do próximo, homem com homem ou qualquer dos dois sexos com animais; a mulher que deu à luz, até o $60^{\circ}$ dia, conforme o sexo do filho, será impura (40 dias se menino; 66 se menina); comer camelo, arganaz, lebre, porco (porque não possuem unhas fendidas e, ao mesmo tempo, ruminam); cobra, crocodilo (porque andam sobre o ventre); siri, camarão, caranguejo (têm muitos pés e, além disso, vivem nas águas, mas não têm barbatanas nem escamas); polvo, jacaré, rã e todos os demais animais que vivem nas águas, mas não possuem barbatanas nem escamas - tudo é impureza e abominação (Levítico, 7:26-27 e 30; 11:4-47; 12:2-5; 18:19-23). A procriação figura como necessidade estratégica de sobrevivência étnica: às agruras do meio geográfico, aos ataques das tribos inimigas, à urgência pelo crescimento demográfico. Esse contexto confere um caráter quase sagrado ao sêmen, que não podia ser desperdiçado. A procriação é, assim, construída como uma bênção sagrada atribuída aos judeus pela sua divindade: "Sede fecundos, multiplicai-vos e enchei a terra" é o comando presente em três pontos do Gênesis, os últimos com outras palavras: "Te multiplicarei extraordinariamente" e "de ti farei uma grande nação" (SILVA, 2004, p. 38; Gênesis 1:28, 9:1, 17:2; 12:2). Nesse quadro, portanto, a esterilidade implica o comprometimento da viabilidade demográfica e do poderio étnico e religioso da tribo, sendo representada em termos religiosos como castigo. A demanda por braços militares e mão de obra agropastoril transforma a extensão da prole em fator de prestígio no interior da comunidade etnorreligiosa e valoriza o nascimento de machos em detrimento de fềmeas. O homem figura como o centro do poder e da estrutura simbólica; esposa era um bem equivalente às rezes, ao gado. $\mathrm{O}$ valor atribuído à mulher se 
resume a sua capacidade procriativa, suas funções religiosas no interior da família e seu papel de gestora dos ciclos femininos de fertilidade e do parto. Daí, o porquê de a poligamia ser institucionalizada no judaísmo, vindo a ser proibida somente no século XI. O número de esposas, filhos e rezes denotava o volume de riqueza e poder (Gênesis 16; 25:21; 30ss; 1Samuel, 1; Jó 1:1-2; Salmos, 128: 3-6; S1 144:12-13; NEUENFELDT, 2007, p. 2-5; SPENCER, 1996, p. 54).

Spencer, porém, chama atenção para o fato de que a nação hebraica se constituiu rodeada por culturas que tinham uma relação bem diferente com a sexualidade. Ele cita, por exemplo, os hititas e os babilônicos, com suas práticas travestis ${ }^{2}$. Assim, rodeados por tantas culturas (egípcios, canaanitas, fenícios e mesopotâmios), os hebreus tinham sua própria cultura modificada no curso do tempo pelas condições políticas, fato que os levava ora a se mostrar mais permeáveis às influências externas, ora mais refratários, desenvolvendo mesmo intensas rejeições em busca do fortalecimento de sua própria identidade cultural e religiosa, fato comprovável no texto bíblico: "Não fareis segundo as obras da terra do Egito, em que habitastes, nem fareis segundo as obras da terra de Canaã, para a qual eu vos levo, nem andareis nos seus estatutos" (Levítico, 18:3, apud SPENCER, 1996, p. 57). Este autor chama atenção, ainda, para o fato de que, etimologicamente, sodomia abarcava todos os atos sexuais distintos da penetração vaginal, fossem de quais sexos fossem os parceiros (v. nota cinco). Segundo afirma, não existia "nenhum termo preciso no mundo antigo, em qualquer das línguas - grego, siríaco, aramaico ou hebreu -, que significasse homossexual", dado que, em sua opinião, constitui uma "prova robusta de que o conceito de homossexual ou de comportamento homossexual não existia, embora a idéia de amor ou relações sexuais entre pessoas do mesmo sexo fosse ocasionalmente mencionada" (SPENCER, 1996, p. 58).

Também no cristianismo, tributário do judaísmo, a sexualidade é construída como pecado ou, na melhor das hipóteses, um mal necessário à contenção da lascívia e meio estratégico para fornecimento de mão de obra e guerreiros, capaz de viabilizar projetos de expansão e domínio. Paulo de Tarso, apóstolo dos mais influentes no cristianismo primitivo, autor de textos que conformam parte bastante significativa do Novo Testamento, é autor de uma hierarquização dos pecados, formada por cinco categorias, uma das quais com quatro subgrupos: 1) os pecados contra Deus; 2) contra a vida do homem; 3) contra o seu corpo (pecados da carne): a) fornicarii (pornoi); b) adulteratio; c) molles (malakoi); d) os masculorum concubitores (homens que dormem juntos); 4) contra os bens e as coisas (propriedade); 5) os pecados da palavra. Segundo Ariès, instaura-se, assim, uma nova ideologia, influenciada pelo estoicismo. Para Tarso, seria preferível que se abstivessem do casamento; em não sendo possível, é o meio legítimo para extravasar os desejos não 
dominados - "é melhor casar do que arder" (ARIĖS, 1987, p. 53). Diante de sua estruturação moral, é possível constatarmos a ordem de valor por ele atribuída à prática de atos sexuais entre pessoas do mesmo sexo anatômico, ou seja, o seu grau de gravidade - o último lugar entre os pecados da carne. De forma semelhante, é possível perceber o silêncio que ele relega às práticas eróticas entre mulheres.

No contexto da ascensão do cristianismo, reprimir o erotismo fazia parte das estratégias para a consolidação do poder político da Igreja Católica, realizada com a antagonização dos valores presentes na Antiguidade pagã - por contraste, portanto (RICHARDS, 1993, p. 137). Nesse período, relações sexuais entre homens era parte integrante da cultura romana. Não representavam nenhuma monstruosidade; seus praticantes, nenhuma espécie humana diferenciada. Tratava-se simplesmente de legítimo exercício do prazer; algo da mesma ordem que a gastronomia, as artes ou o erotismo heterossexual. Os estoicos, ao condená-las, o faziam em decorrência de seu ideal ético contrário às paixões - quaisquer que fossem, por enfraquecer ${ }^{3}$ o vigor desejável ao cidadão-soldado. A busca era por uma existência pautada na racionalidade, livre da vulnerabilidade trazida pelo sentimento, pela emoção. Segundo Veyne, Artemidoro - filósofo grego e autor de obras sobre quiromancia e interpretação dos sonhos, que viveu na segunda metade do século II, contemporâneo de Marco Aurélio e Galeno - definia as relações com escravo, fosse esse homem ou mulher, entre aquelas "conformes à norma". Contrárias eram as incestuosas. Em desacordo com a natureza, ou seja, aquilo "que não está de acordo com as regras sociais", eram "a bestialidade, a necrofilia e as uniões com as divindades" (VEYNE, 1987, p. 40). Este mesmo autor esclarece ainda que não existiam práticas homófilas apenas entre os gregos; elas eram igualmente comuns entre os romanos: "o chamado amor grego poderia ser chamado amor romano com igual legitimidade [...]. $\mathrm{O}$ surpreendente não é que uma sociedade conheça a homofilia, mas que a ignore: o que merece explicação não é a tolerância romana e sim a intolerância dos modernos" (VEYNE, 1987, p. 42).

Enquanto na Grécia as relações sexuais entre homens se estruturavam preponderantemente em termos educacionais, com trocas recíprocas de atributos (saber, experiência, paciência, habilidade $\mathrm{x}$ coragem, força, velocidade, resistência, masculinidade), em Roma se davam, sobretudo, entre senhores e escravos (DOVER, 1994, p. 275-278). Na Grécia, o jovem educando (eromenos) adotava a posição subordinada, inclusive sexualmente; o adulto educador (erastes) assume o papel dominante. Ao crescer, o erotomenos ia assumindo a posição de pupilo e, daí, a de amigo de seu erastes. Ao tornar-se berbe, as relações eróticas eram desaprovadas, tinham de acabar, ainda que os envolvidos se amassem (DOVER, 1994). O que era intensamente desaprovado na 
Grécia era o cunnilingus. Dover documenta referências literárias "com termos de ódio e de nojo tão explicitamente desenvolvidos que temos a impressão de que este assunto era um desafio até mesmo para o senso de humor de Aristófanes"; em Galeno encontra-se a afirmação de que essa prática seria “"mais revoltante' do que a felação” (DOVER, 1994, p. 144-147).

Em Roma, o que era tido como censurável ao cidadão, capaz de atribuir desprezo, era o deixar-se penetrar - traço que se observa presente entre os latinos até os nossos dias. Entre romanos, como entre nós, veem-se abundantes as injúrias rituais e os jogos humorístico-provocativos tendo como objeto a sodomia passiva. Ameaças de penetrar o inimigo como forma de subjugá-lo, de ostentar o domínio sobre ele, são igualmente comuns na contemporaneidade como entre os romanos pré-cristãos. O desprezo contra o passivo sexual era tão intenso a ponto de ser expresso por dois termos: impudicus e diatithemenos. Veyne crê que a condenação decorria da representação pouco viril atribuída a essa posição sexual. Entretanto, outras práticas eróticas que também mereciam condenação infamante eram a felação e a cunilíngua ${ }^{4}$, tidas como o auge do rebaixamento, talvez a censura maior se devesse não tanto à posição adotada pelo corpo do agente/paciente, mas, sobretudo, ao ato de se pôr a serviço, isto é, de igualar-se à posição de servo, de escravo. Povos guerreiros, romanos e gregos, enalteciam os atributos conferidos a sua concepção de virilidade, policiando e estigmatizando todo e qualquer detalhe que pudesse ser visto como atentatório a esse valor estruturante (VEYNE, 1987, p. 42-45; DOVER, 1994, p. 275-278). Entretanto, a forma com que ambos se relacionavam com a sexualidade diferia profundamente.

A cultura grega não desqualificava a bi ou a homossexualidade. Ao contrário: a norma paradigmática era a bissexualidade. A alternância na direção do desejo era algo tão "natural" (comum, usual) a ponto de inexistirem substantivos referentes a "homossexual" ou "heterossexual" (DOVER, 1994, p. 13). No entanto, a natureza intrinsecamente bissexual da sexualidade humana (e, de resto, a animal) na cultura ocidental somente será estabelecida com Freud no século XIX e, ainda assim, para ser silenciada pouco depois. Entre os gregos, contudo, era perfeitamente reconhecida, existindo "grande abundância de testemunhos" de sua modalidade masculina, a comprovar "sua aceitação da alternância de preferências homossexuais e heterossexuais num mesmo indivíduo, e sua negativa implícita de que esta alternância ou coexistência criasse problemas específicos para o indivíduo ou para a sociedade" - apesar de constituírem tribo em constante ameaça de guerra, a necessitar, portanto, de garantir representatividade demográfica (DOVER, 1994, p. 13-14). Contudo, embora receptivos à homossexualidade, expressando-a de forma espontânea na literatura e 
nas artes visuais, eles entendiam que "nenhum homem penetra outros homens e se submete à penetração por outros homens numa mesma fase de sua vida" (DOVER, 1994, p. 13).

Segundo o mesmo autor, faltam fontes capazes para elucidar quando e por que se deu a profunda transformação no modo de sua recepção, que passa de "aberta e sem repressão", documentada já desde o início do século VI a.C., para se tornar algo "tão conspícuo da vida grega" (DOVER, 1994, p. 14). Os indícios da alteração da cultura grega poderiam ser identificados a partir do domínio macedônico (segunda metade do século IV a.C.), intensificando-se com a sua anexação ao Império Romano (ano 146 a.C.), quando se registra a extinção da expressividade de sentimentos e pensamentos, então predominante (DOVER, 1994, p. 16-17). Dover afirma que, ao longo do período clássico - de $\mathrm{V}$ a.C. ao início do século IV a.C. -, existiram variações nas práticas sexuais entre homens (DOVER, 1994, p. 14 e 256). Entretanto, as práticas homófilas jamais mereceram repreensão.

O que era socialmente desqualificado, a ponto de interditar o cidadão ao exercício dos seus direitos civis, era a eventualidade do exercício da prostituição ("a prostituição é sempre e necessariamente ilegítima"). Os gregos acreditavam que o fato de se permitir que alguém pudesse colocar o próprio corpo a serviço do prazer de outrem denotava "que não hesitaria, tampouco, em vender os interesses da comunidade como um todo". Em outras palavras, a prostituição, compreendida como o ato de "pagar a um ateniense para usá-lo como desejar", se colocava sob o mesmo registro acima referido de "prestar um serviço", "servir... como subordinado", ou seja, ocupar o lugar do submetido e, portanto, do indigno. Estes se constituíam em lugares e posições simbólicos fortemente desqualificados naquela cultura, que, ademais de guerreira, era extremamente ciosa de sua democracia e de seu senso de igualdade absoluta entre os cidadãos (DOVER, 1994, p. 36-37; 46-47; 70-71). A condenação da prostituição, porém, não significava a reprovação da homossexualidade; o que a lei visava era à qualidade da pessoa (cidadão ateniense) e não ao ato comercial de alugar o próprio corpo (DOVER, 1994, p. 52).

$\mathrm{O}$ grau de indignidade atribuído à prostituição na cultura pode ser comprovado pela penalidade instituída àqueles denominados hybristes, isto é, pessoas com inclinação para prática de qualquer ato que viesse a colocar o outro em posição de dominado, inferiorizado: maus tratos, arrogância, soberba, desprezo, indignidade, ultraje. A prostituição, quando praticada por um cidadão, significava uma modalidade de hybris - "tais desonras e atos de hybris sobre o corpo de Timarco"; "ele não se incomodou com a hybris cometida sobre o seu próprio corpo"; "transgredir contra a decência tentando usar o corpo de alguém por dinheiro é comportamento digno de um 
hybristes" (DOVER, 1994, p. 59). Hybris, portanto, significava tratar o outro de forma a não the reconhecer dignidade e autodeterminação; tratá-lo como a um dominado, isto é, como escravo, desrespeitando-lhe a posição de igual em direitos estabelecida em lei. Desonrar, desmerecer o status social de outro cidadão era tão grave que a cultura grega estabelecia a mais severa punição, podendo até mesmo ser a morte; nenhuma atenuação era admitida em razão de eventual riqueza, influência política ou estado de embriaguez do agressor. A prática de hybris representava uma ofensa à comunidade inteira: não apenas a figura da vítima era agredida, mas toda a estrutura social e jurídica grega; era o seu valor axial, constituído pela dignidade pessoal, decorrente do princípio da igualdade absoluta entre os cidadãos (homens livres; soberanos de si), independentemente "de riqueza, força ou influência" (DOVER, 1994, p. 56-57).

Em Roma, com a adoção do cristianismo pelo Império, deflagra-se a imposição de códigos legislativos extremamente rigorosos comparativamente ao período não cristão. Segundo Mott, a primeira normativa que sancionou a sodomia entre homens no Ocidente ocorre em 342 com o Edito de Constantino II, modificado em 390 por Teodósio (MOTT, 1988, p. 1). É quando o Cristianismo torna-se a religião oficial do Império Romano. Constantino II sanciona a atitude passiva na relação entre homens, acredita-se, com a castração; Teodósio, entretanto, o amplia de modo a abranger todos os passivos que se prostituíam em bordéis. A pena agora é a fogueira. Posteriormente, em 533, Justiniano edita uma codificação ainda mais rigorosa: a pena de morte para todos os tipos de atos sexuais praticados entre homens, sob a alegação oficial de que "por causa destes crimes ocorrem fomes coletivas, terremotos e pestes", embora se especule que o motivo real seria a perseguição de opositores. Ele também proibiu o divórcio consentido (TORRÃO FILHO, 2000, p. 95). Inicia-se, assim, a satanização das práticas sodomíticas ${ }^{5}$ sob o cristianismo, até então abundantes e visivelmente reconhecidas culturalmente. Sua condenação durante os primeiros dez séculos seguintes à elevação do cristianismo como religião oficial romana, no entanto, jamais se deu de forma contínua e inflexível (TORRÃO FILHO, 2000, p. 107; 108; 96-97).

Apesar dessas primeiras ondas persecutórias, entre fins do século VI e o século XII, a presença da sodomia recuperou sua visibilidade. No período da Baixa Idade Média, precisamente a partir do século XIII, porém, tem início outra onda persecutória ${ }^{6}$, agora violentíssima. Vainfas informa que, além de não ser contínua, a perseguição do cristianismo em face da homofilia era seletiva: "pouco rigorosa antes do século XII e violentíssima nos séculos XIII e XIV; mais indulgente com crianças e adolescentes do que com os adultos; menos severa com mulheres do que 
com homens; mais hostil em relação a clérigos do que com respeito a leigos" (VAINFAS, 1992, p. 70).

No contexto das grandes e reiteradas calamidades (fomes coletivas, enchentes, pestes diversas) e de novas ameaças ao seu prestígio, a Igreja mais uma vez utiliza-se da repressão sexual, em especial às sexualidades ditas antinaturais, para tentar recuperar seu poder político. Ela sentia-se ameaçada diante da proliferação de movimentos ascéticos e com o descrédito de seus dirigentes perante a população (decorrente de práticas como simonia, intensa sexualidade e casamento). A séria crise demográfica, instaurada com as sucessivas pestes - principalmente a Negra, que chega a dizimar um terço da população da Europa ocidental -, faz surgir uma onda de histeria. Em seu rastro, práticas sexuais não procriativas (“desperdício do Sêmen”, ou molície) e práticas contraceptivas (coitus interruptus, coito inter foemora - entre coxas - e abortamento) passam a merecer controle obsessivo, veiculadas como pecados pavorosos, sujeitando seus agentes a perpétua danação.

\section{Notórios e abundantes}

Homens sodomitas eram presença marcante em diversas cidades da Alemanha, Itália, Normandia e Inglaterra. Em Veneza, eram encontrados em todos os setores da sociedade, sem exceção, sobretudo no interior do clero, em que ainda no século III regulamentações foram editadas, tendentes a suprimir todo e qualquer contato íntimo entre os monges (PRECEITOS de São Pacômio, 286-346, cf. TORRÃO FILHO, 2000, 92).

A disseminação das práticas eróticas masculinas era tão intensa a ponto de produzir subcultura peculiar e vigorosa que vicejava em todos os espaços públicos (de frequência homossocial masculina) - boticas, ginásios, casas de massa, escolas, casas de banhos e barbearias -,

dotada de formas de expressão (gírias e poesia erótica) e satisfação sexual próprias, como a prostituição masculina. Com o surgimento de mais uma onda persecutória no contexto do cristianismo, em fins do século XII e que se estenderá por todo o século XIII, são instituídas penas que vão de penitências, flagelações públicas e surras a vultosas multas, perda de bens, decapitação e morte na fogueira (com expropriação do patrimônio). A determinação em instaurar uma nova ordem moral, diante da ampla incidência de práticas sexuais entre homens, pode ser aquilatada por meio da decisão do Concílio de Siena, que em 1234 institui a figura do caçador de sodomitas (RICHARDS, 1993, p. 34 e 137-139; 142-150). 


\section{A mulher, sujeito oculto}

Do ponto de vista da sodomia feminina, no entanto, a disparidade entre os gêneros irá tornar os atos eróticos entre mulheres ao abrigo do quase absoluto silêncio, protegendo a maioria das suas praticantes das sanções aplicadas contra os homens e levando diversos autores a defender a hipótese de inexistência ou escassez de práticas eróticas entre mulheres.

Brown esposa a tese de que, antes do século XIX, as mulheres que praticavam atos sexuais com outras mulheres não se percebiam nem eram percebidas como pessoas diferentes, integrantes de um grupo distinto. $\mathrm{Na}$ sua argumentação, o confinamento aos espaços privados as impediu da construção dessa percepção e também da eclosão de subculturas sexuais específicas (BROWN, 1987, p. 38). Segundo essa autora, as dificuldades de compreensão das práticas eróticas de mulheres entre si estão refletidas na ausência de uma categorização específica. Para Brown,

[...] a sexualidade lésbica não existia. Nem mesmo as lésbicas. Apesar de a palavra 'lésbica' aparecer uma vez no século XVI na obra de Brantôme, não foi usada habitualmente até o século XIX, e mesmo então era mais aplicada a uma série de atos do que a uma categoria de pessoas. (BROWN, 1987, p. 27).

Viñuales, entretanto, afirma que foi o mesmo senhor de Brantôme (Pierre de Bourdeille) quem recuperou e difundiu o termo tríbade em suas Memórias, datadas de 1587. Por três séculos, continua Viñuales, esta seria a única palavra a definir as práticas amorosas entre mulheres, tendo assumido diversos sentidos (VIÑUALES, 2000, p. 51).

Com a emergência do movimento feminista no contexto das revoluções de 1848 e em total oposição à visão dominante na literatura do século anterior, que havia construído uma imagem negativa de "femmes damnées" ou mulheres condenadas, em alusão ao suicídio de Safo, verifica-se a releitura da imagem da poeta e da forma de representação das práticas lésbicas. Expressão de mecanismo compensatório, segundo Elias, constrói-se uma imagem heroica e revolucionária de Safo, e o seu suicídio passa a ser atribuído à luta pela liberdade política (ELIAS, 2000, p. 19-50). Essa nova representação se dá principalmente por meio da ressignificação literária da obra da poeta da ilha de Lesbos, esforço no qual Baudelaire teve um papel bastante notável. Essa nova significação, segundo Viñuales, instaura um paradoxo sobre a visão da lesbianidade ao final do século: portadora de uma patologia, segundo a medicina, e heroína, perante a literatura moderna, usufruindo da liberdade erótica plena, semelhantemente aos homens (VIÑUALES, 2000, p. 51-52). 
Embora se verifique a quase completa ausência de registros sobre a homossexualidade feminina, diversos são os termos específicos utilizados para referir-se às mulheres que mantinham relações afetivo-sexuais entre si (e não apenas práticas sexuais): sáficas, tribades ${ }^{7}$, fricatrizes ${ }^{8}$, viragos, são os mais conhecidos. O que tem levado historiadoras e historiadores a indagar a respeito da sustentabilidade da tese categórica de que tais práticas inexistiam, pelo simples fato de não se encontrar uma consciência diferida com base nelas (identidade autonomeada) ou uma subcultura diferenciada, ao contrário do registrado para os homens. No interior dessa nova historiografia, Torrão Filho nos faz recordar que os comportamentos não nascem apenas quando lhes damos um nome (2000, p. 13). Cita John Boswell, historiador e professor em Yale, que adverte: "o fato de que as fontes históricas não prestem atenção a um fenômeno concreto não prova de forma alguma que ele não tenha existido, nem cabe equiparar a sua descoberta à sua criação ou invenção" (BOSWELL apud TORRÃO FILHO, 2000, p. 13).

Dadas as circunstâncias históricas que condicionavam o ser mulher à incapacidade de compreender a possibilidade de prazer sexual sem a presença do falo (MOTT, 1987; PORTINARI, 1989); ao desconhecimento de sua anatomia e fisiologia; a sua existência circunscrita aos espaços privados nos quais se encontrava segregada; ao desprezo e ao medo com que, de modo geral, eram vistas $^{9}$; à representação delas ora como portadoras de uma natureza intrinsecamente maligna, diabólica ("frívolas, ardilosas, avarentas e de inteligência limitada"), justificadora dos esforços para a sua "disciplinarização"10, ora como a Mãe Divinal - símbolo santificado da maternidade (geradora do valor maior, por conta das crises demográficas: a prole); ao não reconhecimento do direito de gerir suas próprias vidas, corpos e bens; e ao tabu que envolvia a busca do prazer sexual ${ }^{11}$, infração inadmissível à hegemônica finalidade procriativa, o que mais deveria surpreender é a eventualidade da existência de alguma fonte que documentasse esse tipo de conduta em sua vertente feminina. Por outro lado, encontrando-se alijadas do poder, percebidas e representadas como seres inferiores e incompletos, às mulheres resultava sinal de prudência e bom senso manter determinados costumes e especificidades ao abrigo da curiosidade desqualificadora e punitiva dos homens - senhores de todo poder (BELLINI, 1987, p. 39-49; 61; BROWN, 1987, p. 14; VAINFAS, 2004, p. 120-124, 136).

Levando-se em conta tais fatores, resulta problemática a tese que afirma ter sido escassa a manifestação do amor sáfico, respaldando-se na pouca quantidade de registros disponíveis sobre sua manifestação e na não localização de registros sobre a produção de subculturas, ao contrário do documentado para os sodomitas masculinos e pederastas. Na opinião de Bellini, a existência mesma do tratado de Sinistrari contradiz essa tese da inexistência de práticas lésbicas, devendo ser vista 
mais como prova de sua reiterada manifestação do que de sua escassez. Ao enfrentar o total desconhecimento sobre a mulher, seu corpo e formas de prazer, a confecção do tratado por Sinistrari funciona, na verdade, como um testemunho da contumácia desse tipo de erotismo. É princípio assente que esforços normatizadores emergem ante a demanda concreta da realidade social. Não se regulam situações hipoteticamente consideradas, mas fatos sociais concretos.

Embora a referência da construção do ser "homossexual" seja dada por Foucault como ocorrente no século XIX, com a patologização das pessoas portadoras dessas práticas sexuais, para Bellini o processo de constituição dessas pessoas como um tipo específico, na verdade, remonta ao século XVI, com o tratado de Sinistrari a representar um poderoso marco, principalmente no tocante às atividades lesbianas (BELLINI, 1987, p. 48). Pautando-se pela linha argumentativa formulada por Bellini, é possível recuar ao século XI esse marco para as mulheres, quando é publicado o penitencial (manual fixador de penitências, para orientação dos confessores) de Burchard de Worms - Decretum, que se tornará bastante influente. Nesse documento é expressamente reconhecida a existência de práticas sodomíticas entre mulheres, sendo-lhe fixada a pena de cinco anos de penitência a pão e água ${ }^{12}$ (RICHARDS, 1993, p. 40). No século XIII, santo Alberto Magno também faz menção às práticas entre mulheres, ao definir a sodomia como "a prática de sexo entre homem e homem ou entre mulher e mulher".

Do ponto de vista da não visibilidade das práticas "lésbicas", o que parece mais plausível é quase não ter havido previsão de um tipo penal específico para as mulheres, fato que revela mais aspectos de privacidade, maior segredo, desconhecimento e desprezo pela mulher (VAINFAS, 2004, p. 139) do que, necessariamente, menor ocorrência de práticas eróticas entre elas. Diante disso, mais apropriado talvez fosse problematizar essa certa suavização na persecução punitiva, como faz Vainfas, ao destacar o pouco aprofundamento que o inquisidor adotava nos interrogatórios relativamente aos homens acusados de sodomia (VAINFAS, 2004, p. 137-139).

Mesmo diante da maneira ambígua e marcadamente insignificante com que os homens percebiam as mulheres e tudo o que lhes dizia respeito, sobrevivem registros sobre práticas sáficas em todas as esferas sociais, semelhantemente às sodomíticas: vão do palácio (o esquadrão sedutor de Catarina de Médicis) à Senzala (Guiomar Pisçara e Méscia), passando pelos exércitos (Catharina Link) e conventos - a abadessa Benedetta Carlini (BROWN, 1987; BRIGITE apud VAINFAS, 2004; VAINFAS, 2004, p. 115-139; BELLINI, 1987; MOTT, 1999).

Como, então, asseverar com segurança acerca da intensidade ou não de suas ocorrências? O que sabemos nós do que efetivamente ocorria nas relações cotidianas de mulheres abrigadas em 
espaços distantes dos controladores olhares masculinos? O que sabemos sobre as relações entre amas e aias? Quais os efeitos desse modo de percepção das práticas sodomíticas das mulheres (e das práticas eróticas das mulheres, de um modo geral) em termos de produção de fontes? Quanto de verdade existe nas afirmações perante $o$ inquisidor, se consideradas as sanções a que estavam sujeitas, de que a maioria dos atos não passava de pueris folguedos de crianças? $\mathrm{O}$ que concretamente podemos afirmar que sabemos da sexualidade de mulheres relegadas à indiferença ou à inferioridade total? Como, afinal, ter alguma certeza sobre a tão propalada pouca frequência do amor entre mulheres se, conforme ressalta Wolff, "muitos homens encaram o lesbianismo como piada ou, no máximo, uma excentricidade divertida [...]’” Diante dessas circunstâncias, concordo com esta autora de que "foi a arrogância masculina que protegeu as mulheres homossexuais de sofrer o mesmo grau de perseguição que sofreram os homens homossexuais" (WOLFF, s/d, p. 15) ${ }^{13}$.

Com relação à adoção pela mulher do gênero social masculino, parece haver distintas recepções, conforme o contexto. Segundo Brown, não desencadeava nenhum sentimento de ameaça ao domínio masculino. A estrutura de poder total pela qual estavam os homens investidos fazia com que vissem os desvios de gênero de modo distinto, conforme o sexo que o praticasse - o homem efeminado era severamente repelido e censurado, enquanto a masculinização na mulher era percebida semelhantemente a uma rebeldia infantil (BROWN, 1987, p. 21).

Vainfas, entretanto, registra dois casos de travestismo punidos com a morte. Um, em 1580 (ao que parece, por ter chegado a celebrar núpcias), integrante da descrição feita por Montaigne de "sete ou oito mulheres que tinham escolhido vestir-se e viver como homens" (VAINFAS, 2004, p. 124). O outro, segundo Vainfas, o mais documentado, seria o da alemã Catharina Linck, constante no livro de Brigite Eriksson. Catharina teria lutado como soldado em vários exércitos, adotado diversos nomes e identidades e contraído núpcias com a mesma mulher, Margareth - em dois ritos diferentes, no luterano e no católico. ${ }^{14}$

Essa relativa não visibilidade da mulher e de suas práticas fora da norma também se refletiu nas pesquisas. Segundo Viñuales, até os anos de 1990 a maioria das investigações realizadas nos países considerados de primeiro mundo permaneceu sustentando que o lesbianismo era uma prática menos institucionalizada ou visível do que a homossexualidade masculina, por força das características biológicas das mulheres. Duas pesquisadoras, contudo, apontam para aspectos de maior relevância. Uma, em 1980, afirmando que a causa dessa diferença deve ser buscada nas estruturas de poder que organizam as relações entre os gêneros (Carrier), e outra, em 1991, apontando para o contexto histórico (Blackwood), uma vez que, até o final do século XIX, os 
sexólogos definiam a lésbica exclusivamente como mulher dotada de comportamento e atitudes masculinizadas. Com isso, todos os outros modos de expressão do amor entre mulheres passavam despercebidos, diluídos sob o manto da amizade feminina (VINCENT-BUFFAULT, 1996, p. 162173).

\section{O paradigma científico}

Foucault (2005), como já foi antecipado, postula ter sido a partir do século XIX que as práticas eróticas entre pessoas do mesmo sexo passaram a ser tidas como característica individualizante, uma marca considerada distintiva da pessoa, em decorrência da ampliação dos saberes médico e psiquiátrico. Guash, entretanto, defende que um dos marcos desse processo de construção do indivíduo "homossexual" pode ser considerado em 1857, com a publicação do livro Estudo médico-legal sobre os delitos contra a honestidade, de Tardieu, e a configuração física que ele procura fazer dessas práticas. Sua linha explicativa, tendente a encontrar no corpo físico as marcas, os sinais denunciadores dos desvios, será seguida posteriormente por Lombroso, em 1875 (GUASH, 2000, 70). Há, porém, quem discorde. Bellinni, como visto anteriormente, argumenta que esse esforço por transformar em identidade o que significava meras condutas seria simplesmente o seguimento do processo presente desde o século XVIII (BELLINI, 1987, p. 48) - linha de raciocínio que nos permitiria recuar o marco até o século VI, com a instituição da pena de morte pelo imperador Justiniano para coibir práticas sodomíticas (RICHARDS, 1993, p. 145 e 142-143). Mott, por seu turno, defende que havia "homossexuais" antes da invenção desse termo, dados os registros históricos que documentam a existência de subcultura peculiar em Portugal durante a Inquisição, dotada de

[...] nichos privativos, adoção de traços materiais e comportamentais peculiares, com uma gramática, discurso e código de comunicação que permitiam falar de si próprios como uma 'jurisdição' [...] partilhando valores culturais básicos, identificando-se e sendo identificados como pertencentes a uma categoria distinguível da sociedade global (MOTT, 1988, p. 120-139).

De qualquer modo, o fato é que os portadores dessas características, então tidas como degenerativas da sanidade física ou moral, passam a ser objeto de práticas científicas que igualmente os classificam à sua revelia. Submetidos, portanto, a todo um repertório de práticas 
interventivas sob o pretexto de sua cura (FOUCAULT, 2005, p. 43-44; BELLINI, 1987, p. 32-33; TREVISAN, 1986, p. 105-129; GREEN, 2000, p. 193-249; LAQUEUR, 2001). Nesse processo, grande influência tiveram as obras de vulgarização das teorias médicas (GREEN, 2000, 237). Um extenso trabalho de descrição e classificação desses seres, representados como aberrantes, se desenvolve. O "homossexual" (pederasta, invertido, etc.) será construído em função dos modos de representação de seus desejos eróticos, de suas práticas sexuais e, principalmente, a partir do que foi interpretado como sendo seus "sinais psicológicos característicos".

Embora a principal perspectiva da explicação biológica originariamente buscasse construir na sociedade uma visão mais compreensiva para expressões do desejo dirigido a outro do mesmo sexo anatômico, de modo a atenuar a persecução criminal a que eram submetidos gays, lésbicas, travestis e transexuais, ela terminou por possibilitar o surgimento de formas de controle e repressão bem mais sofisticadas.

Os termos "homossexual", "homossexualismo", "homossexualidade" foram usados pela primeira vez em dois textos anônimos em defesa dos direitos homossexuais, publicados em Leipzig no ano de 1869, dirigidos ao Ministro de Justiça Leonhardt e atribuídos a Karl-Maria Benkert (FÉRAY, 1981). Benkert era um escritor, jornalista e poeta nascido em Viena, na Áustria. Em 1845, obteve legalmente o direito de usar a grafia húngara de seu nome, Károly Mária Kertbeny, com a qual ficou conhecido. No contexto da unificação alemã, Kertbeny tinha receio de que o código penal prussiano de 14 de Abril de 1851 passasse a vigorar em todo o território unificado. O parágrafo 143 desse ordenamento criminal sancionava as relações sexuais entre homens como atos contra a natureza. Ele então escreveu diversos textos que argumentavam que tais práticas representavam, na verdade, uma característica inata e não modificável, pelo que não deveriam ser tratadas no âmbito da lei penal, que as via como produto da corrosão do caráter. Afirma-se que a argumentação construída na ação política de Kertbeny era uma estratégia. Ele, intencionalmente, buscava o deslocamento de campo - do criminal para o da medicina - como alternativa para construção de uma imagem mais positiva e tolerante para os praticantes. Na medida em que obtivesse o convencimento de que essa forma de desejo thes era inerente e, portanto, não contrária à natureza, eles não seriam mais vistos como criminosos (VIÑUALES, 2000).

Não foi bem-sucedido, porém. Unificada a Alemanha, a penalização constou no Código Penal do Império Alemão de 15 de maio de 1871, em seu parágrafo 175, vigorando em todos os estados germânicos, assim como na Inglaterra, embora desde o Código de Napoleão, de 1804, a homossexualidade não fosse mais penalizada na França, e no Brasil, desde o Código Criminal do 
Império, de 1830, igualmente sob a influência napoleônica (LAURITSEN y THORSTAD, 1974, p. 19-26; MOTT, 2006, p. 4). Durante a vigência do regime nazista, o parágrafo 175 foi intensivamente utilizado quando se desencadeou a política de perseguição e eliminação de homossexuais em campos de concentração e câmaras de gás, independentemente de processo e prova. Embora ao longo dos anos tenha sofrido atenuações, essa normativa penal somente foi completamente revogada em 10 de março de 1994, com a reunificação da Alemanha, tendo vigido nas duas nações separadas após a II Guerra Mundial. Nesse contexto, a palavra "homossexual" se referia apenas a relações sexuais entre homens e vinha substituir o termo pederasta, então utilizado (VIÑUALES, 2000, p. 36).

Entre 1864 e 1875, o médico alemão Karl Henrich Ulrichs, de quem Kertbeny era seguidor, escreve diversos folhetos em que se reivindicava um tratamento mais humanitário para com os homossexuais, por ele denominados "invertidos" e "uranistas". Em 1862 ele havia publicado uma descrição científica dando conta de que, na fase de desenvolvimento, os embriões eram idênticos; somente num outro estágio adotariam uma das três formas - masculina, feminina ou urning (uranista, em alusão a Urano) - que teria as características físicas de um dos sexos, mas os instintos eróticos, de outro (SPENCER, 1996, p. 274-275; RIOS, 2001, p. 39; LAURITSEN y THORSTAD, 1974, 24). Também Wesphal, psiquiatra alemão, em 1869, Kraft-Ebing, em 1885, com seu livro Psicopathia Sexualis, e Havelock Ellis, em 1897, com Inversão Sexual, irão participar da construção do homossexual.

Em 1897, Magnus Hirschfeld, médico, pesquisador e militante alemão, precursor da moderna sexualidade, cria em Berlim o Comitê Científico-Humanitário, em que desenvolvia e incentivava pesquisas sobre a sexualidade, homossexualismo, prostituição e alcoolismo. Sua opinião era que a homossexualidade resultava de "secreções glandulares" e que seus praticantes "possuíam virtudes especiais" (SPENCER, 1996, p. 307-308). Hirschfeld, ele mesmo militante homossexual, em que pese sua luta pela descriminalização da homossexualidade, terminou igualmente por contribuir de forma involuntária para reforçar os estereótipos da inversão dos gêneros aplicados sobre o "pederasta" e a "lésbica" e a sua representação enquanto um ser distinto e, pior, enfermo congenitamente (TAMAGNE, 2001, p. 92-97). ${ }^{15}$

Assim, ao longo da maior parte do século $\mathrm{XX}$, o que foi originariamente proposto como mecanismo supressor da perseguição criminal vem a se consolidar como fundamento da estigmatização, legitimando as ações de "tratamento" e "cura". Desse modo, a disciplinarização do desvio, da diferença, é obtida pelo discurso da "ciência". Historicamente provadas como meio 
bastante eficaz, as técnicas disciplinadoras se utilizaram de campos científicos (médico, endócrino, genético, biológico, jurídico, antropológico, religioso), fazem uso de retóricas as mais diversas, e não lhes faltam a dialética erística - esse jogo argumentativo que opera para manter a dominação e a segregação, utilizando-se da própria diferença. ${ }^{16} 17$

Com o desenvolvimento das ciências humanas (antropologia, psicologia, sociologia), pôdese compreender que a natureza humana e animal são essencialmente bissexuais - termo oriundo da embriologia e do darwinismo, adotado pela sexologia em fins do século XIX (ROUDINESCO e PLON, 1998, p. 71; 350-351).

\section{A psicanálise}

Freud e os que o seguiram retomaram a noção de bissexualidade como um conceito central para a compreensão da sexualidade. $\mathrm{Na}$ psicanálise, a bissexualidade passou a expressar a disposição psíquica inconsciente inerente a toda subjetividade humana. Compelido pela cultura, o sujeito há que realizar uma "escolha" (inconsciente, e não fruto de uma vontade autônoma, deliberada) em relação a essa propensão bissexual que lhe é intrínseca. Dessa forma, no processo de construção da própria subjetividade, ele terminará por apresentar seu desejo dirigido (orientado) ou para pessoas de seu próprio sexo biológico, ou para aquelas do outro sexo, ou para ambos os sexos.

Essa "escolha" (ou recalque, como chamam os psicanalistas) de uma das direções do desejo terminou por ser compreendida pelo público leigo como se fosse uma "opção" livre, e não como um trabalho inconsciente. Por força da desqualificação historicamente desferida sobre a homossexualidade em nossa cultura, passou-se a atribuir o caráter de "opção" exclusivamente à homossexualidade. Assim, representada como manifestação "imoral", "pecadora" e "antinatural" da eroticidade, a homossexualidade foi sendo compreendida como expressão de um caráter intrinsecamente desprezível, porque desconforme com o padrão dominante de sexualidade.

Já a heterossexualidade, estabelecida agora como paradigmática, ou seja, como a única reconhecida e aprovada, tende a não ser percebida como igualmente fruto daquele mesmo processo inconsciente de "escolha", ou seja, de recalque. Compreendida a heterossexualidade como "a verdadeira e correta" expressão do desejo, o aspecto de "opção" é atribuído apenas àqueles e àquelas que ousam afastar-se do "bom caminho" - ou seja, da heterossexualidade.

Freud, entretanto, hostilizava fortemente "qualquer forma de diferencialismo e discriminação". Numa nota de 1910, no seu "Três ensaios sobre a teoria da sexualidade", de 1905, 
afirmou que "a investigação psicanalítica opõe-se com extrema determinação à tentativa de separar os homossexuais dos outros seres humanos como grupo particularizado" (FREUD apud ROUDINESCO e PLON, 1998, p. 352). Ele a compreendia como uma das modalidades da sexualidade humana e animal (que é intrinsecamente bissexual), "retirando dela qualquer caráter pejorativo, diferencialista, não igualitário ou, inversamente, valorizador". O aspecto de escolha que lhe atribuía era da ordem do inconsciente, como sempre fez questão de ressaltar.

Em uma carta datada de 9 de abril de 1935, escrita em resposta a uma mãe estadunidense que se queixara da homossexualidade do filho, Freud escreveu:

A homossexualidade não é uma vantagem, evidentemente, mas nada há nela de que se deva ter vergonha; não é um vício nem um aviltamento, nem se pode qualificá-la de doença. [...] É uma grande injustiça perseguir a homossexualidade como um crime, além de ser uma crueldade. (FREUD apud ROUDINESCO e PLON, 1998, p. 353).

\section{Disputas de poder no campo}

A partir de 1921, entretanto, o modo de compreensão da homossexualidade pela psicanálise passou a exibir extrema intolerância, abandonando-se as concepções defendidas por Freud. Por todo o mês de dezembro de 1921, os integrantes do Comitê Secreto, órgão dirigente da International Psychoanalytical Association (IPA), se debatiam, divididos entre uma visão científica e outra, repressora. A primeira, representada pelo grupo de Viena e, a segunda, pelo de Berlim. Entre os segundos, se destacavam Karl Abraham e Ernest Jones. Consideravam os homossexuais incapazes para o exercício profissional da Psicanálise. Jones chegou a declarar que a homossexualidade "era um crime repugnante: se um de nossos membros o cometesse, atrairia para nós um grave descrédito". Precisamente ele que, durante sua estada no Canadá, fora acusado de abuso sexual.

Integrante do grupo vienense, Otto Rank, apoiado por Freud, exerceu importante resistência aos segregacionistas: "Não podemos rechaçar essas pessoas sem outra razão válida, do mesmo modo que não podemos admitir que elas sejam perseguidas pela lei."

Desgraçadamente, porém, diante da pressão corporativa de Ernest Jones e dos berlinenses, os integrantes desse comitê secreto capitularam, inclusive Ferenczi e Freud. A homossexualidade passou então "a ser banida da legitimidade freudiana, a ponto de ser novamente considerada uma ‘tara"” (RANK apud ROUDINESCO e PLON, 1988, p. 353). 
Assim, por mais de cinquenta anos e já pelo poder das sociedades psicanalíticas estadunidenses, dominantes na IPA mediante a APA, a psicanálise seguiu engendrando mecanismos e posturas as mais repressivas e desqualificadoras, afastando-se definitivamente da compreensão freudiana. No entanto, a fim de se esquivar de qualquer acusação de prática discriminatória, os dirigentes da IPA jamais formularam por escrito as regras desse entendimento. Ninguém menos do que Anna Freud, filha de Sigmund Freud, o fundador, tomou para si o grande papel de desvirtuar as formulações de seu pai. Um de seus feitos mais emblemáticos foi pedir à jornalista Nancy, do jornal The Observer, para não publicar a célebre carta acima referida, datada de 1935, em resposta à mãe do homossexual.

Foi somente na segunda metade do século XX, com Lacan, que se deu início à cisão nesse processo repressor (ROUDINESCO e PLON, 1998, p. 350-355).

\section{Despatologização}

O agrupamento das doenças segundo suas características comuns é conhecido por nomenclatura ou nosologia. Trata-se de um sistema que reúne doenças "análogas, semelhantes ou afins", de forma hierarquizada, isto é, a partir de um padrão ou eixo classificatório. Foi apenas em 1893, muito graças ao trabalho de William Farr, que surgiu uma classificação passível de utilização prática. Era a Classificação de Bertillon, adotada pelo Instituto Internacional de Estatística. No século XX tornou-se uma classificação internacional de doenças. Até essa época, as informações sobre a frequência das doenças apenas se relacionavam com as estatísticas de suas morbidades. A Associação Americana de Saúde Pública recomendou fosse adotada pelos países da América do Norte, sugerindo sua revisão a cada dez anos. A partir da sexta, em 1948, instituída em 1950, a atribuição de revisar, publicar e divulgar a Classificação Internacional de Doenças passou a ser da Organização Mundial de Saúde (LAURENTI, 1991, p. 407-417).

O Manual Diagnóstico e Estatístico de Transtornos Mentais (DSM) é o documento elaborado pela APA que estabelece os critérios a serem observados pelos psiquiatras na construção de seus diagnósticos. Foi publicado pela primeira vez em 1952 e, depois, em 1968 (DSM II). Era pouco divulgado na sociedade. Restringia-se ao campo psiquiátrico. Dada a hegemonia da APA no mundo ocidental, ele é adotado entre nós. Em 1968 também foi publicada a versão VI da Classificação Internacional de Doenças, a CID-6. Ambas as classificações contemplam as mesmas 
categorias, porém a DSM traz algumas divisões e subdivisões diferenciadas, inclusive categorias novas.

Em sua terceira versão, em 1980, o DSM reflete a mudança de paradigma, em curso desde os anos de 1960, e acolhe as novas conclusões encontradas por pesquisadores como Kinsey e Evelyn Hooker. Refletindo as demandas da comunidade médica e da sociedade, o DSM-III deixa de classificar a homossexualidade como transtorno mental, o que já havia sido estabelecido pela APA em sua reunião anual de 1973. Em 1987 é publicado o DSM-III-R, versão revisada do DSM-III. De sua elaboração, precedida por intensas discussões, participaram não somente médicos psiquiatras, mas também os ativistas homossexuais. O processo formal teve início em 1977, mas as discussões institucionais ocorreram nas Conferências Anuais da APA de 1970 a 1973. Por indicação do Presidente da Associação, os trabalhos foram liderados pelo psiquiatra Robert Spitzer, conceituado professor de psiquiatria da Universidade de Colúmbia (DERBLI, 2011; ANGELL, 2011, p. 48).

No Brasil, em 1985 finalmente é noticiada a supressão da homossexualidade do rol de transtornos mentais elaborado pelo Conselho Federal de Medicina, no qual figurava sob o Código 302.0 da Classificação Internacional de Doenças (CID). Era o resultado de intensa campanha deflagrada pelo Grupo Gay da Bahia em outubro de 1981, integrando-se os mais diversos grupos então existentes, além de intelectuais e pesquisadores nacionais e internacionais e de um abaixoassinado que reuniu vinte mil assinaturas (MíCCOLIS, 1983, p. 109-110; Boletim do GGB, n. ${ }^{\circ}$, 1982, p. 1; MASCARENHAS, 1985). Em 1994 foi publicada a versão em vigor, o DSM-IV. Há previsão de publicação do DSM-V em 2013, com a expectativa de supressão de diversas parafilias ou fetiches, em razão do entendimento atual, por parte de psicólogos e terapeutas, de que se trata de simples expressão da sexualidade. Verifica-se, ainda, a tendência de excluir a travestilidade dessa edição.

$\mathrm{Na}$ opinião do psiquiatra Daniel Carlat, porém, os diagnósticos elaborados pela psiquiatria "são subjetivos e expansíveis" (CARLAT apud ANGELL, 2011, p. 49). Diferentemente da maioria das outras especialidades médicas, "não há sinais ou exames objetivos para as doenças mentais", o que possibilita "expandir fronteiras do diagnóstico ou até mesmo criar novas diagnoses, de uma forma que seria impossível, por exemplo, em um campo como a cardiologia” (ANGELL, 2011, p. 49).

Apenas em $1 .^{\circ}$ de janeiro de 1993, com a entrada em vigor da Revisão 10 da CID, o "homossexualismo" (práticas homossexuais) deixa de figurar como doença. A primeira Conferência Internacional para a Décima Revisão da Classificação Internacional de Doenças, convocada pela 
Organização Mundial de Saúde, se deu em 1984. Sua denominação por extenso passou a ser Classificação Estatística Internacional de Doenças e de Problemas Relacionados à Saúde. Mantém, contudo, a abreviatura antiga (CID). Ela estabelece que "a orientação sexual por si não deve ser vista como um transtorno" (DATASUS). Lamentavelmente, porém, a ausência de rigor conceitual em sua versão brasileira adota indistintamente "orientação" e "preferência" sexual, o que em meu entendimento contribui para a confusão acerca da natureza não volitiva do processo de constituição da orientação do desejo sexual. O Centro Colaborador da OMS para a Família de Classificação Internacional em Português é o Centro Brasileiro de Classificação de Doenças, da Faculdade de Saúde Pública da Universidade de São Paulo, USP (CID-10, v.2, 2008).

A partir dos anos 1960, em decorrência das profundas transformações desencadeadas pelos novos movimentos sociais nos planos político, cultural e científico, verifica-se cada vez mais a adoção da perspectiva culturalista e interdisciplinar, em vez da exclusivamente psicológica ou psiquiátrica, no que respeita à orientação sexual, identidade e papéis de gênero.

\section{Sintoma, não etiologia}

$\mathrm{Na}$ psiquiatria, em 1954, estudos realizados por Evelyn Hooker demonstraram que o quadro psicológico apresentado pelos "homossexuais" era na verdade resultado da estigmatização social a que eram submetidos, e não uma característica de sua natureza, comprovação que leva à transformação na forma de sua abordagem (VIÑUALES, 1999, p. 37).

A partir de meados dos anos de 1970, a antropologia ocupa um papel relevante no esforço de compreensão da "homossexualidade" - desejo e práticas sexuais entre pessoas do mesmo sexo enquanto legítima expressão do desejo humano, recepcionada e representada de modos distintos, de acordo com a estrutura de significados de cada cultura. Nesse percurso, com os questionamentos quanto aos métodos empregados nas pesquisas etnográficas e a atenção para as relações de poder que organizam as estruturas simbólicas, categorias como homossexualidade, heterossexualidade, identidade e papéis de gênero deixam de ser apreendidas de maneira fixa e universal e passam, cada vez mais, a ser examinadas no interior dos contextos sociais nos quais estão integradas. Também foi possível a compreensão de que sexo, gênero, sexualidade e direção do desejo não são absolutamente variáveis plasmadas umas às outras, mas, ao contrário, apresentam-se na realidade empírica de forma completamente dissociada (PARKER, 2001, p. 125-150; VIÑUALES, 2000, p. 36-40). 
Em outras palavras, a partir do intenso debate teórico que se seguiu às pesquisas que documentavam práticas eróticas entre pessoas do mesmo sexo em distintas culturas - finais dos anos 80 e início dos 90 do século XX -, a própria definição da homossexualidade foi questionada. Como defini-la? A partir da identidade de gênero? Do objeto do desejo? Das práticas? Da autoatribuição? Qual, afinal, seria o elemento definidor? E as pessoas que não consumam seus desejos, embora os portem? E aquelas que vivenciam longas relações com pessoas do mesmo sexo e, posteriormente, outras com pessoas do sexo distinto? É possível falar de "homossexualidade" em contextos nos quais inexiste a noção de "heterossexualidade"?

Por outro lado, constatou-se que os modos de estruturação de gênero e sexo em nossa sociedade contaminaram os modos de análise realizados pelos pesquisadores em outras sociedades, principalmente quando se depararam com a adoção, por um gênero, de trajes, adereços e gestual característicos de outro gênero (caso dos Hijras, na Índia; dos Xanith, em Oman; e dos Berdaches, na América do Norte). Tais etnocentrismos levaram à interpretação de que tais usos - muitos dos quais ritualísticos, de cunho religioso - fossem lidos como necessariamente implicados com práticas sexuais entre pessoas do mesmo sexo físico, descuidando-se de atentar sobre como essas pessoas eram definidas no interior de sua comunidade e sem comprovar se efetivamente mantinham relações sexuais com outros indivíduos de seu mesmo sexo anatômico. Tal constatação deu curso a outras interrogações: Como se engendra uma dada estrutura de gênero? Quais são os limites entre um e outro polo da classificação? (VIÑUALES, 2000, p. 36-40). E como manter no interior desse sistema classificatório binário e opositor indivíduos que constroem sua trajetória em relações, ora no padrão tradicionalmente classificado como 'homossexual", ora na padronização de ‘heterossexual” (NAVARRO-SWAIN, 2000, p. 94)?

\section{Etemo retorno?}

Em reação às liberdades conquistadas com a chamada Revolução Sexual e com o advento dos movimentos homossexuais, a partir de meados da década de 1980, no lastro da pandemia da AIDS, observa-se o ressurgimento de uma onda conservadora no País. Diversas denominações religiosas neopentecostais assomam no cenário cultural a disputar consciências e corpos. Nesse processo destacam-se duas personagens no Brasil: o missionário R. R. Soares, fundador da Igreja Internacional da Graça de Deus, e Edir Macedo, cofundador, juntamente com Soares, em 1977, da Igreja Universal do Reino de Deus. Com interpretação a-histórica e literal da Bỉblia, fazem coro à 
Igreja Católica Romana, opondo-se ferrenhamente às recém-conquistadas liberdades sexuais. Reafirmam visões preconceituosas a respeito de gays, lésbicas, travestis e transexuais. Atribuem aos homossexuais a "culpa" pela origem do HIV-Aids; condenam o aborto, o uso de preservativo e de anticoncepcional.

A grande diferença é que desenvolvem e põem em prática uma estratégia de tomada do poder. Duas publicações podem ser citadas como representativas: o Plano de Poder: Deus, os cristãos e a política, do Bispo da Igreja Universal, Edir Macedo, escrito em parceria com Carlos Oliveira, diretor-presidente do jornal Hoje em Dia, de Minas Gerais; e Os cristãos no ambiente de trabalho: como o povo de Deus pode transformar a sociedade, de Peter C. Wagner, professor de Crescimento da Igreja no Fuller Theological Seminary School of World Mission, em Passadena, EUA por 28 anos. Ambas tratam de uma e mesma coisa: modos estratégicos de ocupação de espaços sociais e políticos, com vistas a "instaurar o Reino de Deus na Terra". A segunda publicação o faz pela noção de Igreja Estendida - todos os espaços são Igreja (presídios, hospitais, escolas, universidades, casas legislativas, executivas e judiciárias, repartições públicas, condomínios residenciais...) - e a primeira, por meio da ideia de que os cristãos devem se ocupar da política para a implantação do projeto de nação "idealizado por Deus".

\section{Desafio}

Imersos durante o período formativo em ambiente social (familiar, escolar, grupos de atividades e vizinhança) fortemente estigmatizante e refratário à noção de dignidade e autodeterminação enquanto direitos universais, não dispõem os "homossexuais" de suporte positivo sequer dos núcleos mais íntimos e decisivos - como a família e a escola. Assim, constituída desde fora e em bases desqualificadas, a autopercepção que esses indivíduos vão elaborando tende a reproduzir a perspectiva estigmatizada, predominante em nossa sociedade. Para que superem essa imagem deteriorada, hão de elaborar o conflito que se instaura ainda antes que possam ter clareza a respeito dos próprios desejos e identidade (DANIEL, 1983, p. 23-24, 28, 35-36). Esse conflito é resultante da forma de percepção do mundo exterior (oriunda da religião, de certa concepção de moralidade e de ciência), por um lado, e do direito à autodeterminação e à autonomia, por outro (PECHENY, 2004, p. 167). Todo indivíduo - sobretudo aquele alcançado por processos de segregação e estigmatização - possui autonomia para proceder à reapropriação e ressignificação de 
conteúdos desqualificadores a si atribuídos, na legítima busca pelo seu bem-estar. Esta é a luta na qual se encontram envolvidos desde o século passado, em todos os países do mundo.

\section{Referências bibliográficas}

ANGELL, Marcia. A epidemia de doença mental. Revista Piauí, n. 59, ano 5, agosto de 2011. ARIÈS, Philippe ; BÉJIN, André (Orgs.). Sexualidades ocidentais. 3. ed. São Paulo: Brasiliense, 1987.

BOSWELL, John. Les unions du même sexe : dans l'Europe antique et médiévale. Paris: Fayard, 1996.

BERBLI, Marco. Uma breve história das revisões do DSM. Revista Com Ciência de jornalismo científico. SPBC, 20/03/2011. Disponível em:

http $/ /$ www.comciencia.br/comciencia/handler.php?section=8\&edicao=64\&id=815\&print=true

Acesso em: 20/03/2012.

CID-10. vol. 2. Classificação Estatística Internacional de Doenças e Problemas Relacionados à Saúde. Décima Revisão. Vol. 2. Manual de Instrução. OPAS/OMS/USP. Tradução: Centro

Colaborador da OMS para a Família de Classificação Internacional em Português. 8. ed. revista e ampliada. São Paulo: Edusp, 2008. Disponível em:

http//books.google.com.br/books?id=s469 WXryq4C\&pg=PA172\&lpg=PA172\&dq=conferencia + internacional+revis\%C3\%A3o+classifica \%C3\%A7\%C3\% A3o+internacional+doen\%C3\% A7as\&so urce=bl\&ots=n8PAEjI_d3\&sig=H0vydWKz6ezUyY9rr1ps1ch6fkM\&hl=pt-

BR\&sa=X\&ei=LrNvT7 ztNMzoggfih7Fr\&ved=0CEsQ6AEwAw\#v=onepage \&q=conferencia\%20in ternacional $\% 20$ revis\%C3\%A3o\%20classifica\%C3\%A7\%C3\%A30\%20internacional $\% 20$ doen\%C3 \%A7as\&f=false. Acesso em: 20/03/2012.

DANIEL, Herbert. Os anjos do sexo (Crômica e Notas Marginais). In: MÍCCOLIS, Leila \& DANIEL, Herbert. Jacarés \& Lobisomens: dois ensaios sobre a homossexualidade. Rio de Janeiro: Achamé/Socii, [s.d.].

DATASUS. Relatório da Conferência Internacional para a Décima Revisão da Classificação Internacional de Doenças. Versão 2008. Disponível em:

http $/ /$ www.datasus.gov.br/cid10/v2008/webhelp/relatorio_da_conferencia.htm\#Relat8. Acesso em: 21/03/2012.

DOVER, K, J. A homossexualidade na Grécia antiga. Tradução de Luís Sérgio Krausz. São Paulo: Nova Alexandria, 1994.

FÉRAY, Jean Claude. Une historie critique du mot homosexualité. Revue Arcadie. Janvier/avril, 1981. 
GREEN, James. Além do carnaval: a homossexualidade masculina no Brasil do século XX. São Paulo: Unesp, 2000.

Jornal Lampião da Esquina, n. 32, janeiro de 1981.

LAQUEUR, Thomas. Inventando o sexo: corpo e gênero dos gregos a Freud. Rio de Janeiro: Relume-Dumará, 2001.

LOPES, Paulo Roberto. Nos anos 50, Igreja Católica da Holanda castrou jovens gays. Disponível em: http $/ /$ www.paulopes.com.br/2012/03/nos-anos-50-igreja-catolica-da-holanda.html. Acesso em: $17 / 03 / 2012$.

MACEDO, Edir; OLIVEIRA, Carlos. Plano de poder: Deus, os cristãos e a política. Rio de Janeiro: Thomas Nelson Brasil, 2008.

MOTT, Luiz. Pagode português: a subcultura gay em Portugal nos tempos da Inquisição. Ciência e Cultura (SBPC/SP), vol. 40, fevereiro 1988.

Etno-história da homossexualidade na América Latina. Comunicação apresentada no Seminário-Taller de História de las Mentalidades y los Imaginarios, realizado na Pontíficia Universidad Javerina de Bogotá, Colômbia, Departamento de História e Geografia, 22-26/8/1994.

. Revista Estudos Feministas, Florianópolis, 14(2), p. 509-521, maio-agosto/2006.

NAVARRO-SWAIN, Tânia. O que é lesbianismo. São Paulo: Brasiliense, 2000.

NEUENFELDT, Elaine Cleici. Fertilidade e infertilidade na Biblia: suspeitas a partir da teologia feminista. Revista Aulas. Dossiê Religião, no 4, abril-julho 2007. Disponível em: http:/www.unicamp.br/ aulas/Conjunto\%20I/4_3.pdf._Acesso em: 10/03/2012.

PARKER, Richard. Cultura, economia política e construção social da sexualidade. In: LOURO, Guacira Lopes. O corpo educado: pedagogias da sexualidade. Belo Horizonte: Autêntica, 2001.

PECHENY, Mario. Identidades discretas. In: RIOS, Luís Felipe; ALMEIDA, Vagner de;

PIMENTA, Cristina; TERTO JÚNIOR, Veriano. Homossexualidade: produção cultural, cidadania e saúde. Rio de Janeiro: ABIA, 2004.

RICHARDS, Jeffrey. Sexo, desvio e danação: as minorias na Idade Média. Rio de Janeiro: Jorge Zahar, 1993.

ROUDINESCO, Elizabeth; PLON, Michel. Dicionário de Psicanálise. Rio de Janeiro: Jorge Zahar, 1998.

TAMAGNE, Florence. Mauvais genre?: une historie dês représentations de l'homosexualité.

France: Lamartiniere, 2001.

TORRÃO FILHO, Amícar. Tríbades galantes, fanchonos militantes: homossexuais que fizeram história. São Paulo: Summus, 2000. 
TREVISAN, João Silvério. Devassos no paraíso: a homossexualidade no Brasil, da colônia à atualidade. 3. ed. revista e ampliada. São Paulo: Record, 2000.

VAINFAS, Ronaldo. Casamento, amor e desejo no ocidente cristão. São Paulo: Ática, 1992.

VIÑUALES, Olga. Identidades lésbicas. Barcelona: Bellaterra, 2000.

WAGNER, C. Peter. Os cristãos no ambiente de trabalho: como o povo de Deus pode transformar a sociedade. São Paulo: Vida, 2007.

WOLFF, Charlotte. Considerações preliminares. In: WOLFF, Charlotte. Amor entre mulheres. Rio de Janeiro: Nova Fronteira, [s. d].

\section{Notas}

1 Lésbicas, gays, travestis e transexuais.

2 Indivíduos de um sexo que usam roupas, adereços e gestual atribuídos culturalmente a pessoas de outro sexo biológico.

3 Amolecer; tornar frouxo, lasso; de molle; mollities. Presumível alusão ao estado de letargia geral que acomete os corpos após o orgasmo. Vainfas, apoiando-se em Ariès, historiciza o emprego do termo, dando conta de que nos primórdios da cristandade representava um conjunto de atos eróticos que tinham a finalidade de proporcionar maior e mais duradoura sensação de volúpia, adiando ou evitando a conjunção carnal. Posteriormente, foi abrangendo diversas variedades de atos sexuais sem penetração, mas com ejaculação. Depois do século XII, porém, passa a significar variadas "práticas solitárias", entre elas a masturbação. No século XIV elabora-se uma distinção entre "poluções manuais" e molície, definindo-se as primeiras como não necessariamente solitárias, ao contrário da segunda, que, a partir do século XV ou XVI, passou a significar basicamente a masturbação masculina solitária, também referida como "crime de Onam", devido ao desperdício do sêmen. Enquanto a busca de prazer solitário no homem merecia penas que variavam de sete a trinta dias a pão e água ou jejum de cinquenta dias, caso o praticante fosse um bispo, as mulheres recebiam a penitência de "quarenta dias de jejum durante um ano ou mais" (Cf. VAINFAS, 1992, p. 62-64).

${ }^{4}$ Veyne destaca o quanto as culturas grega e romana estavam em oposição à japonesa, na qual o samurai sentia-se orgulhoso e deliciado em proporcionar todos os meios de prazer às mulheres (VEYNE, 1987, p. 45). Como visto acima, a cultura grega era mais tolerante em relação à felação e fortemente censória quanto à cunilíngua.

5 A sodomia também mereceu uma variedade de significados: de violação aos costumes humanos para a sexualidade, passa depois a abranger uma noção de natureza, ao contrário de costumes, seguindo para uma ideia de desvios da genitalidade (coito anal e poluções orais de ambos os sexos). O terceiro significado apontado por Vainfas vincula o termo estreitamente à prática de sexo anal, notadamente aquelas entre homens (século XIII). Tida como uma exacerbação do desejo "carnal", após o século XII passa a ser compreendida como "um desvio radical da natureza" (Cf. VAINFAS, 1992, p. 64-67).

6 Para o contexto colonial brasileiro, ver TREVISAN, 1986, 2000; BELLINI, 1987; VAINFAS, 2004; MOTT 1999, 1987. Estes dois últimos produziram outros trabalhos igualmente importantes, e aos quais remeto, sobre o tema no período colonial brasileiro.

${ }^{7}$ O Dicionário Houaiss registra o surgimento do termo em 1877, oriundo do grego tribás, tribádos, derivação do verbo tribõ (HOUAISS, 2001, p. 2.765). Aulete atribui a origem do termo ao grego tribein - esfregar (AULETE, 1964, p. 4.057). Bellini registra o termo na obra toda dedicada ao assunto, de autoria do teólogo italiano Luigi-Maria SinistrariDe sodomia (Tratactus in quo exponitur doctrina nova de sodomia faeminarum a tribadismo distincta) - cuja data de publicação ela encontrou referências como sendo 1700, em Roma (BELLINI, 1987, p. 39-40). Viñuales cita o registro de Bonnet em seu livro sobre relações amorosas entre as mulheres, onde dá conta de que o primeiro registro do termo tríbada foi realizado pelo poeta latino Marcial, no Século I, referindo-se a uma cortesã de nome Philaenis (VIÑUALES, 2000, p. 51).

${ }^{8}$ Segundo Bellini, tríbades e fricatrizes eram as classificações presentes no tratado elaborado por Sinistrari para as mulheres que utilizavam instrumentos fálicos em suas relações com outras mulheres (BELLINI, 1987, p. 45-46). 
9 A exuberância erótica da mulher deflagrou uma onda de temor e repressão contra sua sexualidade. As mulheres passaram a ser construídas ainda na pré-modernidade europeia como "de índole carnal", "lascivas", "devassas", portadoras de incontida insaciabilidade em sua luxúria carnal. No período moderno tem-se a consolidação desse processo, com a mulher e seu sexo anatômico sendo vistos como terrivelmente intimidatórios. Sobre essa sexualidade vibrante e ávida será desencadeado um processo - que se provará bastante eficaz - de condenação, controle e punição, de modo a quase aniquilá-la. Uma das estratégias foi construir-lhe outra imagem, diametralmente oposta - a de mãe sublime, sagrada guardiã dos filhos e do marido, recatada e casta (BELLINI, 1987, p. 51-54). Richards registra que os dois modelos com funções enobrecedoras construídos para as mulheres (a Virgem Imaculada e a Mãe) foram promovidos a partir da emergência do culto à Virgem Maria, nos séculos XI e XII (RICHARDS, 1993, p. 36).

${ }^{10}$ Segundo Richards (1993, p. 36), "a lei canônica permitia especificamente o espancamento da esposa, e isto acontecia em todos os níveis da sociedade".

${ }^{11}$ Definido como "pecado mortal", ainda que entre marido e mulher. Segundo Richards, "somente no final do século XVI a idéia de sexo puramente por prazer foi apresentada como uma proposição teórica séria", tendo mesmo havido sua proibição expressa no século IV por são Jerônimo - “Um homem que está ardentemente apaixonado por sua esposa é um adúltero"” (RICHARDS, 1993, p. 34).

12 No contexto medieval, os desvios mais graves eram o incesto, a sodomia, a bestialidade e o abortamento. Masturbação mútua e sexo entrecoxas entre pessoas do mesmo sexo (homens), no entanto, eram tidos como de menor gravidade. Por outro lado, sexo oral, penetração vaginal por trás e o chamado coito dorsal (a mulher por cima) eram severamente punidos. O primeiro provavelmente em razão do desperdício do sêmen, o segundo era visto como destituindo o homem de sua dignidade, ao aproximá-lo das posições praticadas pelos animais, segundo Richards, e o terceiro como se subvertendo a posição dominante reservada exclusivamente ao homem. Também era severamente punido "qualquer ato que conduzisse à excitação sexual ou ao prazer sexual". Nesse contexto, se a mulher ingerisse o sêmen de seu marido, "a fim de inflamar seu desejo", estava sujeita à penitência de sete anos a pão e água. (RICHARDS, 1993, p. 40-41).

${ }^{13}$ Wolff documenta o alto grau de segredo e temor que envolve a lesbianidade, em contexto das últimas décadas do século XX, em que inexiste pena de morte ou flagelação, apenas o banimento social: "Encontrei bastante dificuldade para obter um número suficiente de pessoas para as minhas investigações [ela entrevist ou 108 mulheres] porque muitas lésbicas temiam a possibilidade de que transpirassem as informações que poderiam me prestar. Essa atitude me surpreendeu, pois várias organizações lésbicas ofereceram a garantia de uma discrição absoluta nos apelos feitos para a minha pesquisa. O fato de estar, como médica, presa ao sigilo profissional deveria bastar, em si, para dissipar qualquer medo. A organização lésbica Kenric publica uma circular mensal em que não se faz referência ao sobrenome de nenhuma associada [...]. Tal medida denota grande receio da opinião pública. Também notei outra atitude igualmente esquiva durante as entrevistas. Muitas vezes tive de prometer o maior sigilo [...]" (WOLFF, [s. d.], p. 21).

${ }^{14}$ Em suas intimidades com a esposa Catharina se utilizava de um pênis de couro amarrado à cintura, chegando a "molestar" sua parceira. Vainfas também registra outros casos de mulheres que foram punidas por utilizarem instrumentos fálicos, uma, inclusive, no Brasil colonial (VAINFAS, 2004, p. 136, 130).

${ }^{15}$ O Ins tituto Magnus Hirschfled foi destruído juntamente com todo o seu acervo quando da ascensão do nazismo, cujos adeptos acreditavam que a homossexualidade poderia levar a raça alemã à extinção, assim como à propagação da pornografia e à emancipação feminina. Ver também SPENCER, 1996, p. 300.

16 Exemplo eloquente pode ser visto tanto na batalha jurídica daquilo que ficou conhecido como "O caso Seares" (PIERUCCI, 1990), quanto na exposição de motivos do deputado paulista Afanázio Jazadji, em seu Projeto de Lei ${ }^{\circ}$ 705/2003. Segundo a revista virtual Mix Brasil, em sua justificativa o deputado argumenta que a Lei $\mathrm{n}^{\circ}$ 10.948/2001, objeto de revogação pelo seu projeto, ao fixar sanções administrativas para os casos de homofobia estaria "desigualando os iguais [...], desfazendo o princípio de igualdade inerente à natureza humana”. Disponível em: http://mixbrasil.uol.com.br/mundo mix/centralplus/noticia.asp?id=1657.

17 Sobre diferença e igualdade das identidades sociais e de grupo, remeto ao texto de Scott, O enigma da igualdade (SCOTT, 2005, p. 11-30). Agradeço a Lula Ramirez sua socialização por meio de lista de discussão virtual.

Recebido em abril de 2012.

Aprovado em junho de 2012. 